\title{
Use of Social Networking Media in Political Participation: A Study on Dhaka University Students
}

\author{
Ashek Mahmud ${ }^{1, *}$, Ruhul Amin ${ }^{2}$ \\ ${ }^{1}$ Department of Sociology, Jagannath University, Bangladesh \\ ${ }^{2}$ Department of Sociology, University of Dhaka, Bangladesh
}

Copyright $\bigcirc 2017$ by authors, all rights reserved. Authors agree that this article remains permanently open access under the terms of the Creative Commons Attribution License 4.0 International License

\begin{abstract}
The role of social networking websites (SNWs) on offline political activities has gained currency in recent days. This study aims to explore the dynamics of relationship between users of social networking websites and their political participation. A cross-sectional survey was conducted on 110 students in the University of Dhaka. The empirical study focuses on evaluating whether there is relationship or not between SNWs and offline political participation in different respects. The use of SNWs contributes to boosting consciousness about political activity and political awareness. It also studies to find association between time span used up in SNWs and participation in offline political activities. This study concludes that some specific activities in SNWs have role to develop the level of participation in political activities.
\end{abstract}

Keywords Social Network, Social Networking Websites, Political Participation

\section{Introduction}

Social networking website, including Facebook, is the most popular social networking platform in Bangladesh with 18 million active accounts (Daily Star, 29 December, 2015). Around $40 \%$ of the world populations have accessibility to internet connection today in which only $7 \%$ among total population of 160 million have availability and accessibility to use internet in Bangladesh (World Development Report, 2016). Social media including Facebook, blog, and twitter, creates more activism and social movements in present time reflected in political engagement. The use of social networking sites is growing at unbelievable rates amongst both young and experienced citizens (Martin \& Schmeisser, 2008) [19] and supporting to this, Boyd explores that majority of youth and teenagers utilize social networking sites. Social networking websites contribute to maintaining preexisting social networks as well as helping connect with strangers based on shared interests, political views or any other activities (Boyd and Ellison 2008). [5]

Stressing the impact of the proliferation of personal media - devices and their connection to social media channels Ben Calder (2013) noted that "Social media based social relationships in the modern world has been the subject of a significant amount of research" [7]. In this connection, social media websites enhances platforms on the Internet where people interact freely, share and discuss information and ideas on personal and various socio-political issues using combination of verbal, pictorial and audio-visual expression. SNWs users are not only "networking" or looking to meet unknown people but also are primarily communicating with known people among their extended social network. Most importantly Facebook allows registered users to create profiles, upload photos and video, send messages and keep connecting with friends, family and colleagues that help political mobilization. Twitter as a popular micro blogging social site plays significant role in political enlistment through information transmission. Concurrently blogging and email account generate political environment by sending political information to their supporters and well-wishers in order to build protest movement.

It is stated that there is a moderate and positive relationship between intensity of Facebook use and students' life satisfaction, social trust, civic participation and political engagement (Valenzuela and Kee, 2008) [33]. There is an alternative claim that Internet use does not have an effect on the propensity to participate in public life (Quintelier and Vissers, 2008) [27]. From this conflicting claim, doubt raised whether social networking websites contribute to participating in political activities or not. For instance, through using Facebook, blog (Rabbani, 2014) [28] Shahbag movement influenced the protest by disseminating specific types of information (Zamir, 2014) [37] and enriched participants through using social networking websites (Curtis, 2015) [11]. This paper initiates to understand the relationship between using of social networking websites and political participation among Dhaka University students. 


\section{Impact of Social Networking Media on Political Participation}

Mass media are the most important sources of political information, which is identified as an important source of political engagement (Pasek et al., 2006) [23]. The demand for flexibility in defining issues and constructing a political identity has led to the framing of participation based on a more personal, individualistic expression of political action (Calder, 2013) [7]. But there is a debate among the social media researchers on the issue of positive or negative impact of social media on political participation. Few researchers showed positive relationship and other proved as negative. As an example, different patterns of Internet use have different effects (e.g., positive or negative) on the level of political engagement. Solop (2000) similarly argued that younger people are more likely to vote online than the older voters [29]. De Vreese (2007) demonstrated that many internet activities are positively related to different dimensions of civic and political participation [13]. Furthermore Boyd and Ellison (2008) observed that most of the SNWs contribute to maintaining pre-existing social networks as well as helping connect with strangers based on shared interests, political views, or activities [5]. On the other hand, use of social media has a negative impact on social and political participation (Putnam, 2000) [26]. This view stresses that the more time people spend online, the more contact they lose with their social environment and the less time they spend to meet their friends and family (Nie , 2002) [22].

Vitak, Smock, Ellison and Lampe (2009) conducted an online random sample survey on 683, Undergraduate students at Midwestern university in U.S.A. on the topic of "Poking people to participate: Facebook and Political Participation in the 2008 Election" [34]. They concluded that political activity in Facebook is significantly associated with political participation. Smith (2013) also examined a telephone interviewed survey on sample of 2,253 adults among English and Spanish people finding that individuals who are politically active on social networking websites are also highly active in offline spaces, and those who are politically active offline tend to have relatively high rates of engagement in social networking spaces [30]. Another web survey of college students in Texas $(n=2,603)$ reveals moderate relationship between intensity of Facebook use and students' life satisfaction, social trust, civic participation and political engagement (Valenzuela and Kee, 2008) [33]. By contrast, Quintellier \& Vissers (2008) clearly argued that spending time in online has no significant role in political participation. They conducted a survey on a representative sample of 6,330 in Belgium and analyzed time spent on the internet and various activities performed online [27]. They found that timeline on the internet does not have an effect on the propensity to participate in public life. But it is important to state that some online activities are clearly and significantly associated with offline political participation. In addition, Mantean (2015) analyzed an online sample survey of 130 Romanian young people on the topic of "The Impact of Social Media Use of Political Participation" and expressed concluding result that online political participation didn't persuade offline politics [20].

\section{Theoretical Framework}

Political sociologist Manuel Castells formed a theory on network society which stated the recent transformation in society as well as changing sociability and forms of social interaction through social network, as individuals are connected with each other by self-selection network which is called socialized communication [9]. Castells (2005) claimed that social media based socialized communications are essential in the formation of consciousness and attitude as well as political decision building [9]. In this context, social network theory emphasizes socialized communication system which is constructed by social networking media that are based on sharing feelings and audio-visual expression. This theory expresses that the electronic hypertext makes horizontal networks of autonomous communication that emerged in the local and global arena strengthening the power of network society in the real world social network [8]. That's why Castells (2005) said that "Internet users are more social, have more friends and contacts and are more socially and politically active....." Castells believes that media is important for building political hegemony or counter hegemony ensuring political participation that shapes political process through socialized communication. ". In addition to that, Castells (2005) commented that "the more they (users of SNWs) use the internet, the more they also engage in face-to-face interaction in all domains of their lives". [9]

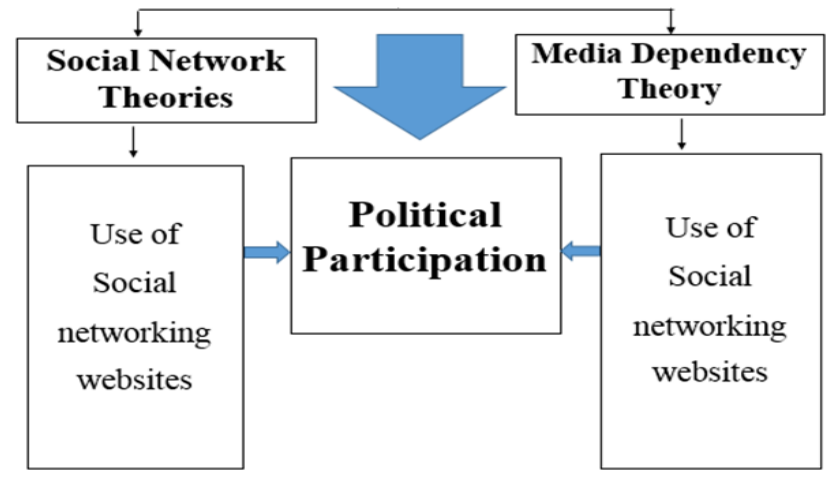

Figure 1. Theoretical framework of the study

Castells's ideas are slightly different from media dependency theory stressing that social networking overall makes people politically active. Baran and Davis(2006) proposed the main proposition of media systems dependency theory as "the more a person depends on having needs gratified by media use, the more important the media's role will be in the person's life, and therefore the more influence 
those media will have[2]. Ball-Rokech and DeFleur (1976) argued that the greater the media dependency in connection with a particular message, the greater the likelihood that the message will alter audience cognitions, feelings, and behaviors [1]. The dependency theory model might also help us to understand the theory of media determinism developed by Marshall McLuhan (1964). He wrote "The effects of technology don't occur at the level of opinions or concepts, but alter sense ratios or patterns of perception steadily and without resistance." [21]

According to technological determinists, particular technical developments, communications technologies or media, or, most broadly, technology in general are the sole or prime antecedent causes of changes in society, and technology is seen as the fundamental condition underlying the pattern of social organization. Technological determinists believe that "'You can't stop progress', implying that we are unable to control technology" ( Green, 2001) [15]. Technological determinism seeks to show technical developments, media, or technology as a whole, as the key mover in history and social change (Kunz, 2006) [18]. Technological determinism has been summarized as 'The belief in technology as a key governing force in society ...' ( Smith, 1994) [31]. In this regard, Postman pointed out the functional role of information media as:

The printing press, the computer, and television are not therefore simply machines which convey information. They are metaphors through which we conceptualize reality in one way or another. They will classify the world for us, sequence it, frame it, enlarge it, reduce it, and argue a case for what it is like. Through these media metaphors, we do not see the world as it is. We see it as our coding systems are. Such is the power of the form of information. ( Postman, 1992) [25]

One of the best examples of technological determinism in media theory is Marshall McLuhan's theory "the medium is the message". According to McLuhan, there is an association between communications media/technology and language; similarly, Benjamin Lee Whorf argued that language shapes our perception of thinking (linguistic determinism). Harold Innis (1951) believed that the social, cultural, political, and economic developments of each historical period can be related directly to the technology of the means of mass communication of that period [17]. Harold Innis's analysis of the effects of communications on the rise and fall of empires led him to warn grimly that western civilization is now facing its own profound crisis as an instance western civilization suffered from an "obsession with present-mindedness" that eliminated concerns about past or future [17]. By contrast, Raymond Williams (1974) criticized media determinism and rather believed social movements define technological and media processes. [35]

In contrast, with the technological deterministic approach, Bennett and Segerberg (2011) introduced Networked Individualism theory that explored public engagement, policy focus, and mass media offering looser organizational affiliations, and coalitions that presented a more rigid protest framework with fewer social media platforms [4]. Rather than a collective appeal for individuals to take action for one particular reason, the online protest offered 'a rainbow of reasons to act' including threats to business and innovation, invasion of privacy, opening up vulnerabilities of the internet, and threats to jobs(Bennett,2012). [3]

In relation to Networked Individualism theory, Social Media's Political Approach implies that in a modern political landscape characterized by the rise of individualism and personalized participation repertoires, people are retreating to the private sphere, resorting to social media activity for their dose of political action - a means of communication which is built on 'mutual privatism' (Fenton and Barrassi, 2011) [14]. According to this approach, within social media networks, with their emphasis on self-empowerment, there is potentially little concern for broader political and social contexts. These contexts involve the dominant framings of acceptable political action and social organization as well as the broader positioning of political activity within neoliberal discourse (Fenton and Barassi, 2011) [14]. Similarly, Ronald F. Inglehart( 1977) constructed Cognitive Engagement Theory (CET) that stresses individuals' will power and learning ability about politics which eventually leads to participation in politics with the efforts of youths[16]. At the time, cognitive mobilization theory basically meant political participation is affected by better educated youths who have increased access to information (Inglehart, 1977[16]). Thus, the core of CET is that political participation is the product of an individual's education, access to information, political knowledge, political interest and policy satisfaction. It noted that political participation is associated with an individual's access to information, political interest and political knowledge exploring that the lesser the cost of access to information the more youths consume information from the media and the higher the level of political knowledge and interest among youths which further leads to increased political participation . [16]

Apart from that, Adaptive Structuration Theory (AST) developed by G. DeSanctis and M. Scott Poole (1994) implies the importance of influential, informational social exchange between politicians and users of social networking sites. The core premise of the AST is the idea that advanced information technologies, like social networking sites, enable multiparty participation and exchange in organizational activities through sophisticated information management (DeSanctis and Poole, 1994) [12]. The AST proposes that this relationship between society and technology, or system and structure, is a two-sided exchange that leads society to a response or "movement" (Turner, 1986). [32]

Another significant theory named 'Political Information Efficacy' has been developed to make confidence in their political knowledge as social media is the best medium to examine young people trends on searching political 
information (Pollock,1983) [24]. Besides that, digital media use is positively associated with political discourse for those lower in political interest (Bruce Bimber, 2014) [6]. An additional complicated theory like Hybrid Media System theory highly focused on the communication networks that were served by the Occupy movement existed in a 'hybrid media system'. Chadwick writes about media hybridity, politics, and power, arguing that a holistic approach to the role played by communication and information in politics is necessary; 'one that avoids exclusively focusing either on supposedly "new" or supposedly "old" media' and hence a hybrid media system is built upon interactions among older and newer media logics (Chadwick, 2013). [10]

\section{Study Design and Methods}

\subsection{Study Region and Sampling Procedure}

Dhaka University has been taken purposively as the study location for data collection as it is claimed that respondents of Dhaka University are more politically sensitive than others. Dhaka University was established in 1921 which is the largest- public university in Bangladesh, with a student body of 33,000 and a faculty of 1,800 that is located in the capital of Bangladesh. - This research has been conducted on particular age, gender, education and class. Prior to start data collection, we pre-test the questionnaire in Jahurul Haq Hall and Rokeya Hall as the residential area of Dhaka University knowing that pre-testing questionnaire gives us valuable insight about the response of the data and questionnaire. Using random selection, the study has been conducted on the both residential and non-residential students of 10 respective halls and a political space of Dhaka University. Among them $67.5 \%$ of the respondents were selected from residential hall and the rest $32.5 \%$ of the respondents were selected from non-residential students with $65.5 \%$ male respondents and $34.5 \%$ females.

We carried out survey method using sample size 110 students from the population of 33,000 students of Dhaka University. A set of structured questionnaire, with open ended and close ended questions, was prepared beforehand that was divided into subsections such as demographic, social networking, political knowledge and activity. The questionnaire was arranged keeping the study objectives in mind.

\subsection{Techniques of Data Analysis}

All survey data were analyzed using SPSS Software for the analysis of factors that determine the relationship between social networking media user and political participation. Data presentation has been completed through using coding system and transforming into percentage that helps to analyze data quantitatively. We analyzed data carefully penetrating connection between the use of social media and rate of political participation. For comparison secondary data were collected from relevant departments, published books and journals.

\subsection{Limitations}

The major limitation of the research is very small sample size as the survey had been conducted with our own limited financial capability. Another drawback of the research is that gender issue doesn't maintain equal proportion between male and female. As female's accessibility of the social media was limited in comparison with the male due to their economic dependency with the family is greater than the male.

\section{Results and Discussions}

\subsection{Background of the Information}

From the study, it has been evident that the greatest number of respondents (55.5\%) have no email account and the rest of them (44.5\%) have minimum one email account although $99.1 \%$ of the respondents have at least one Facebook account that have been used for maintaining social communication. Nevertheless, the highest percentage $(94.5 \%)$ of the respondents said that they never participated in political activities through mail with the $5.5 \%$ rarely sent political email to participate an event, although more than three fourth $(77.3 \%)$ of the users of Facebook account used Facebook daily. The study also reveals that $50 \%$ respondents read post on the political issue in a political Facebook group whereas only $11.8 \%$ enjoy political discussion and $13.6 \%$ comment on the post of political issue. A quarter of them $(24.5 \%)$ ignore political discussion in a Facebook group while they are interested in many of the non- political ideas, concepts and pictures. Other than Facebook account, among the users of twitter account (38.2\%) only $35.5 \%$ respondents said that they posted political twit as most of them had no interest in political issue. 
Table 1. Time spent in social media

\begin{tabular}{llcc}
\hline & DU students & Male & Female \\
\hline & & & \\
Less than 5 hours & 40.9 & 23.63 & 17.27 \\
5-10 hours & 20.0 & 13.64 & 6.36 \\
10-15 hours & 17.3 & 10.91 & 6.36 \\
15-20 hours & 12.7 & 10 & 2.73 \\
20+ hours & 9.1 & 7.27 & 1.82 \\
Number of cases & 110 & 72 & 38 \\
\hline
\end{tabular}

Table 2. Activities of SNWs user on the Social Networking Websites

\begin{tabular}{lcccc}
\hline Activities in SNWs & Yes & Percent & No & Percent \\
\hline Sending email on political issue & 6 & 5.5 & 104 & 94.5 \\
Posting twit on political issue & 38 & 34.5 & 72 & 65.5 \\
Activism in blog websites & 7 & 6.36 & 103 & 93.64 \\
Chat with FB friend & 85 & 77.27 & 25 & 22.73 \\
Update status and comment & 80 & 72.73 & 30 & 27.27 \\
Search/read political news/status & 70 & 63.64 & 40 & 36.36 \\
Share link/status/video & 65 & 59.1 & 45 & 40.91 \\
Following political figure & 64 & 58.18 & 46 & 41.82 \\
Member of political FB group & 79 & 71.8 & 31 & 28.2 \\
Discussion in a political FB group & 82 & 74.5 & 28 & 25.5 \\
Number of cases & 110 & & & \\
\hline
\end{tabular}

This picture clearly shows that most of the students, whether they have Facebook or twitter account, are unaware and unconscious about their political and civil rights and so they have less political concern and willing to political participation using e-mail, Facebook or twitter. If we make comparison among the users of technological network, Facebook users are clearly ahead comparing with e-mail and twitter users. This situation is closely associated with the time period. A half of the respondents use social networking websites less than one hour a day and more than $40 \%$ use SNWs less than five hours a week (see table 1). Further 20, 17.3 and $21.8 \%$ students use social media within the range of 5-10, 10-15 and more than 15 hours a week respectively. According to gender perspective, male participation in Facebook using is higher than the female students as data shows that $23.6 \%$ male and $17.3 \%$ female students use social media less than five hours a week, similarly about a total of
$42 \%$ male and $17 \%$ female use social media more than five hours a week(see table 1).

In this way, data permit us to measure the effects of time spent in online on political participation and political activity as it is argued that more time spent in social networking websites increased political consciousness as well as political activity of the respondents.

\subsection{Linkage of Social Networking Websites with Political Issues}

As stated earlier, the study emphasized the role social media in connection with the political participation, political discussion and political analysis. The analysis of table two reveals that the highest percentage $(94.5 \%)$ of the respondents doesn't send email, $65.5 \%$ don't twit and about $94 \%$ of the bloggers don't use blog website about the 
political issue and subjects or incidents as they are more interested in non-political issues. This result clearly conveys insignificant linkage between the use of email, twitter and blog and political participation or political concern. Although more than three fourth (77.3\%) of the respondents continuously chat with their Facebook (FB) friends and $72.7 \%$ update status and comments on various issues but most of the Facebook users are indifferent to political issues and interest.

As high as 72\% members are involved in Facebook group in which political matters have been discussed and among them $74.5 \%$ respondents said they were engaged in discussion in the Facebook group in which political issues are mentioned. Pew research center (2013) stated that, in $2012,28 \%$ of SNW users said they posted links to political stories or articles, $20 \%$ followed a candidate or similar political figure and $43 \%$ of SNWs users decided to learn more about a political or social issue. On the other hand, the table-2 directly focuses that most of the Facebook users have interest in politics compared with other social networks users. In comparison with Pew research survey, data shows that $63.6 \%$ search political news or status and $59 \%$ share link or status on political comments as $58.2 \%$ have more or less support to some political figures. More than fifty percent $(54.55 \%)$ users expresses that more social networking website use doesn't linked with political purpose but it is helpful to know prevailing situation and in supporting this $59 \%$ agree on the statement that it is possible to know contemporary event from SNWs(data are not mentioned in the table). In connection with this $40 \%$ do agree and $4.55 \%$ do strongly agree that Facebook increases political consciousness through getting political news and comments while $38.18 \%$ neither agree nor disagree.

In fact, brain map suggests that, only specific types of online political activity such as chatting with friends, search political news/ link and read status, share link, status, video, followed political figure and reading their status, updating status and comment in the social networking websites have potentiality to enhance level of offline political participation.

\subsection{Use of Social Media in Political Participation}

Fourteen offline political activities such as attending a rally, giving opinion to radio, TV, newspaper, participating in human chain, motivating people on political issue, raising voice against unequal law, acquiring political knowledge, contacting with a politician, volunteering for political party/ figure, developing knowledge on politician, attending a demonstration, motivating people to political event, giving opinion on political scam, membership of a political party and attending political work in last 12 months are included for study hoping to get a linkage with the use of social media.

Fahmid Al Zaid (2016) stated that nowadays, social media is seen as a tool to mobilize people without any centralized leadership like political parties or trade unions citing example of 'Tanu issue' on rape and murder in Comilla area of Bangladesh and 'No vat' movement of private universities were highly influenced by social media. In connection with this, our survey data (see table-3) portrays that more than fifty percent of the respondents participated in rally (55.5\%), in human chain $(58.2 \%)$, and in any other political work in last year (57.3\%).[36]

Table 3. Political knowledge and Activities of the social networking website users

\begin{tabular}{lcccc}
\hline Offline Political Activities & Yes & Percent & No & Percent \\
\hline & & & & \\
Attend a rally & 61 & 55.5 & 49 & 44.5 \\
Giving opinion to radio, TV, & 22 & 20 & 88 & 80 \\
Newspaper & & & & \\
Attend a human chain & 64 & 58.2 & 46 & 41.8 \\
Motivate people on political issue & 36 & 32.7 & 74 & 67.3 \\
Voice against unequallaw & 62 & 56.4 & 48 & 43.6 \\
Acquire political knowledge & 69 & 62.7 & 41 & 37.3 \\
Contact with a politician & 28 & 25.5 & 82 & 74.5 \\
Volunteering for political party/ figure & 35 & 31.8 & 75 & 68.2 \\
Develop knowledge on politician & 61 & 55.5 & 49 & 44.5 \\
Attend a demonstration & 37 & 33.6 & 73 & 66.4 \\
Motivate people to political event & 35 & 31.8 & 75 & 68.2 \\
Giving opinion on political scam & 40 & 36.4 & 70 & 63.6 \\
Member of a political party & 35 & 31.8 & 75 & 68.2 \\
Attend in political work in last & 63 & 57.27 & 47 & 42.73 \\
12 month & & & & \\
Number of cases & 110 & & & \\
\hline
\end{tabular}


The data also shows more satisfactory and positive attitude on political activities in such way that as high as $62.7 \%$ respondents acquired political knowledge and $55.5 \%$ developed knowledge about politician from social media and for this reason $56.4 \%$ of the respondents raised voice against unequal laws implemented by the ruling party of the state. Further 32.2, 25.5, 31.8 and $33.6 \%$ respondent motivated people to participate in political event, making contact with politician, political party voluntarily and political demonstration correspondingly. As most of the students (68.2\%) have no membership of any political party and as there is inflexible political regulation, most of them (63.6\%) deprived themselves from giving any opinion on political comment and so only $20 \%$ gave opinion on politics to radio, TV or newspaper.

In fact, using social media is highly closed with political activities and related issues such as: political human chain, acquiring political knowledge, raising voice against unequal law, developing knowledge on politician and attending rally. By contrast, using social media is less linked with active participation in political work, motivating people, contacting with politician, voluntary participation and having membership in political party.

\section{Conclusions}

Use of social media is so widespread that it mainly enlarges communication network across the world in everywhere contributing to the not merely communication skill connecting with socio economic development but to enhance socio political awareness including political knowledge, political motivation and involvement in political activities. Thus social media has vast power to serve an insight to the viewer's political engagement. The hypothetical view was that the more they (users of SNWs) use the Internet, the more they engage in face-to-face interaction in all domains of their lives. But empirically close connection between the online activity and offline activity is partially authentic. Although there is little role of email in political discussion and engagement, a greater function of Facebook in relation to political discussion and political involvement cannot be ignored.

We can't say that more active in social media leads to less active in political participation, as viewer and participants are major part of social media. The use of Facebook obviously increases consciousness about political activity, knowledge on political situation, involvement in rally and human chain demanding socio political rights and attending in political work. On the other hand, online communication has little connection with motivating others in political actions, creating political membership and contacting political party. Consequently, it is focused that political environment has been created by social media which has greater impact on building opinion and active participation in political activities in some respect. In this regard, specific types of online political activities augment offline political participation although interest in non-political issues may not be deserted.

We have some recommendation for those users of social networking websites:

- Users of social networking websites should keep far from spreading political scandal related post and sharing the post.

- Rumor or chitchat is also a great problem for the users of social media and so they should be careful about this phenomenon.

- Users should also be careful about false messages that can undermine the trust of people by diffusing, fabricating, and manipulating information.

- In time of election, media politics turns into scandal politics, assuming this, users should have special attention towards this distorted propaganda.

\section{Acknowledgements}

The Authors wish to acknowledge Department of the Jagannath University and the University of Dhaka and to the Students of various departments who provided data with their own volition and also the participants who participated throughout the execution of the project work which has culminated in the formation of this article.

\section{REFERENCES}

[1] Ball-Rokeach, Sandra J., DeFleur, ML. (1976). A dependency model of mass- media effects, Communication Research,3(1): 3-21. doi:10.1177/009365027600300101

[2] Baran, Stanley J., Davis, Dennis K.(2006) Mass Communication Theory: Foundations, Ferment, and Future, Communication Faculty Book Publications.

[3] Bennett, W. Lance. (2012).The Personalization of Politics: Political Identity, Social Media, and Changing Patterns of Participation, The Annals of the American Academy of Political and Social Science, 644.1

[4] Bennett, W. Lance, Segerberg, A. (2011). Digital Media and the Personalization of Collective Action, InformationCommunication and Society, 14.6

[5] Boyd, D., Ellison, N. (2008). Social Network Sites: Definition, History, and Scholarship, Journal of Computer-Mediated Communication, 13(1), 210-230. doi:10.1111/j.1083-6101.2007.00393.x

[6] Bimber, Bruce, C. Marta, C. Lauren, G. Rachel. (2014). Digital Media and Political Participation: The Moderating Role of Political Interest across Acts and Over Time, Social Science Computer Review.

[7] Calder, Ben (2013) Political Participation in the Social Media Moment: the Emergence of Personal Politics, Supervised by Dr. John Postill, Submitted for the degree of Bachelor of 
Media and Communication, School of Media and Communication, RMIT University, US.

[8] Castells, Manuel. (1996)The Rise of the Network Society: The Information Age: Economy, Society, and Culture Volume I. Oxford: Basil Blackwell

[9] Castells, M., Cardoso, G.(2005). The Network Society: From Knowledge to Policy, Johns Hopkins Center for Transatlantic Relations, Washington.

[10] Chadwick, Andrew(2013). The Hybrid Media System: Politics and Power, Oxford University Press, New York

[11] Curtis, AR. (2015). From Arab Spring to Shahbag: The role of Social Media in Terms of National Crisis, J Mass Communication Journalism, 5 (2), 241. doi:10.4172/2165-7912.1000241

[12] DeSanctis, G., Poole, M. S. (1994). Capturing the Complexity in Advanced Technology Use: Adaptive Structuration Theory, Organization Science, 5

[13] De Vreese, C.H. (2005). The spiral of cynicism reconsidered: the mobilizing function of news, European Journal of Communication 20(3): 283-301.

[14] Fenton, N., Barassi,V. (2011). Alternative Media and Social Networking Sites: The Politics of Individuation and Political Participation, The Communication Review 14.

[15] Green, Leila (2001).Technoculture: From Alphabet to Cybersex, Crows Nest: Allen \& Unwin.

[16] Inglehart, R. (1977). The silent revolution: Changing values and political styles among western publics, Princeton, Princeton University, New Jersey.

[17] Innis, Harold. (1951).The Bias of Communication, University of Toronto Press, Toronto.

[18] Kunz, William M. (2006).Culture Conglomerates: Consolidation in the Motion Picture and Television Industries, Rowman \& Littlefield Publishers, Inc.

[19] Martin, K.,Schmeisser, H. (2008). The Effects of Social Networking Websites and Youth Voter Participation, The American Political Science Association Conference and Social Networking and the Future of Politics and Administration Panel, August. Retrieved http://195.130.87.21:8080/dspace/bitstream/123456789/1018/ $1 /$ The $\% 20$ effects $\% 20$ of $\% 20$ social\%20networking\%20websit es\%20and\%20youth\%20voter\%20participation.

[20] Mantean, A.(2015).The Impact of Social Media Use of Political Participation, Master's Thesis, Retrieved fromhttp://pure.au.dk/portal-asb-student/files/90378581/The Impact_of_Social_M edia_on_Political_Participation.pdf

[21] McLuhan, Marshall. (1964). Understanding Media, Routledge \& Kegan Paul, London.

[22] Nie,H. (2002). Internet and Society: A Preliminary Report, It and Society, Volume 1, issue 1, PP. 275-283

[23] Pasek et al.( 2006). America's Youth and Community Engagement: How Use of Mass media is related to Civic
Activity and Political Awareness in 14-22 Years Old. Communication Research, 33 (3). 115-135. DOI:10.1177/0093650206287073

[24] Pollock.(1983). The Participatory Consequences of Internal and External Efficacy, Western Political Quarterly.

[25] Postman, N. (1992). Technology: the Surrender of Culture to Technology, Vintage, New York.

[26] Putnam, R. (2000). Bowling Alone: The Collapse and Revival of American Community, Simon and Schuster, New York.

[27] Quintelier, E., Vissers, S. (2008). The Effect of Internet Use on Political participation: An Analysis of Survey Results for 16-Year-Olds in Belgium, Social Science Computer Review Winter, 26(4), 411-427. Doi: 10.1177/0894439307312631

[28] Rabbani, G. (2014). Shahbag Protest and Nationalism: A Study on Urban Social Movement in Bangladesh, Dhaka UniversityInstitutionalRepositoryPolicy,Retrievedfromhttp://r epository.library.du.ac.bd/xmlui/bitstream/handle/123456789 /631/Golam\%20Rabbani.pdf?sequence.

[29] Solop, F. I. (2001). Digital Democracy Comes of Age: Internet Voting and the 2000 Arizona Democratic Primary Election' PS: Political Science and Politics,34 (2), pp. 289-93.

[30] Smith, A. (2013). Civic Engagement in the Digital Age: Online and offline political engagement. Pew Research Center, Retrieved from http://www.pewinternet.org/cate gory/publications/report/

[31] Smith, M., Marx, Leo, eds. (1994).Does Technology Drive History? The Dilemma of Technological Determinism, MIT Press, Cambridge.

[32] Turner, J. H. (1986). The Theory of Structuration, American Journal of Sociology. 4 (91)

[33] Valenzuela, S., Park, N., Kee, K. (2008). Lessons from Facebook: The Effect of Social Network Sites on College Students' Social Capital, Submitted to the 9th International Symposium on Online Journalism, Austin, Texas, April 4-5. Retrieved from https://online.journalism.utexas.edu/2008/papers/Valenzuela. pdf

[34] Vitak, J., Zube, P., Smock, A., Ellison, N., Lampe, C.(2009). Poking People to Participate: Facebook and Political Participation in the 2008 Election, Paper presented at the annual conference of the International Communication Association, Chicago.

[35] Williams, Raymond (1974).Television: Technology and Cultural Form, Routledge, London and New York.

[36] Zaid, F. (2016, April 4). Armchair activism on social media. Newagebd.net, Retrieved from http://newagebd.net/217466/armchair-activism-on-social-me dia/.

[37] Zamir, Hassan. (2014). Diffusion of Protest Information in Twitter during Shahbag Movement of Bangladesh, Proceedings of the American Society for Information Science and Technology, 51(1), 1-4. doi:10.1002/meet.2014.14505101131 